\title{
A Study of Reputation Effect Restricting the Moral Hazard in C2C E-Commerce
}

\author{
Xiaoying Xu1, Maoran Ye² \\ ${ }^{1}$ School of Management, Jinan University, Guangzhou, China \\ ${ }^{2}$ School of Economics and Management, Southeast University, Nanjing, China \\ Email:986948545@qq.com
}

How to cite this paper: $\mathrm{Xu}, \mathrm{X}$.Y. and Ye, M.R. (2017) A Study of Reputation Effect Restricting the Moral Hazard in C2C E-Commerce. Open Journal of Social Sciences, 5, 260-268. https://doi.org/10.4236/jss.2017.53024

Received: February 6, 2017

Accepted: March 28, 2017

Published: March 31, 2017

Copyright (c) 2017 by authors and Scientific Research Publishing Inc. This work is licensed under the Creative Commons Attribution International License (CC BY 4.0).

http://creativecommons.org/licenses/by/4.0/

\begin{abstract}
Based on repeated game and unilateral moral hazard framework, this thesis studies the formation and evolution of reputation in C2C E-Market and the restriction effect of reputation to the sellers' moral hazard behavior. The research on reputation model shows that the formation of reputation is a dynamic process, which is regulated by sellers in $\mathrm{C} 2 \mathrm{C}$ E-Market. In the market introducing the reputation mechanism, the most effective way to restrict moral hazard behavior is to leverage the sellers' long-term benefits, stabilize the market, and reduce transaction cost.
\end{abstract}

\section{Keywords}

Moral Hazard, Reputation Model, C2C E-Commerce

\section{Introduction}

In regards to E-commerce regulation, the game of reputation-based moral hazard has been a hot issue in the world of academic research. Scholars from home and abroad have conducted research from the following three aspects:

1) The Existence of moral hazard in E-Market and its incentive mechanism design. $\mathrm{Li} \mathrm{Li}$, et al. (2005) and Tianshuai Xie, et al. (2009) verifies that there is certain degree of moral hazard in network transaction, which is divided into the sellers' moral hazard, buyers' moral hazard, and the moral hazard of transaction intermediary and third-party logistics [1] [2]. If the sellers are unable to show the product quality to the buyers in a convincing way, or if the buyers can't promise to fulfill payment obligations, this asymmetric information will make the transactions gradually shrink and even disappear. The present research on moral hazard control and realization of transaction coordination is mainly based on static model and its core countermeasure is to design appropriate incentive contract. However, our social credit system is not well-developed, which can't 
suppress the activities of bad faith [3]. This means that business activities need to more rely on informal regulating mechanism, in particular on its restriction and incentive effect.

2) Research on the theory of the game of reputation-based moral hazard. Xuejun $\mathrm{Yu}$ and Jinjin $\mathrm{Yu}$ [4] use eBay online bidding case as an example, which is a multiplayer-repeated game, to study the cooperative equilibrium led by reputation effect under asymmetric information condition. Jianjun Zhang et al. (2013), probe into the reputation effect on moral hazard in the network context from the suppliers' perspective [5]. But as for the issue of moral hazard in China's domestic network market, their research still lags behind both in theoretic and practical guidance.

3) Reputation's influence on E-Market standardization and integrity. A large number of scholars have studied the reputation effect of eBay's original credit evaluation system and verified reputation's facilitating effect on transaction price, probability of successful transaction, transaction efficiency and consumers' trust, as well as its restriction effect on transaction risks [6] [7] [8] [9]. Domestic scholars verified reputation's positive effect on transaction price, auction success rate and etc., on the basis of the data from Tabao, eBay and other local E-commerce websites [3] [10]. Present theoretic research focuses more on the design of reputation evaluation mechanism and the empirical study of its effect in E-Market, but it lacks analysis of the restriction effect of reputation and other implicit incentive measures on opportunistic behavior [11].

Based on repeated game, this thesis studies the restriction effect of dynamic reputation mechanism on sellers' moral risk-taking behaviors in China's C2C E-commerce transactions. Compared with previous research, this thesis provides basic theory reference for network regulation practices.

\section{Problem Description and Model Assumption}

\subsection{Problem Description}

Over the past years, Taobao, as the representative of China's domestic C2C E-commerce platform, has gradually designed a series of trading mechanisms different from eBay. The main differences are as follows:

1) The influence of sellers reputation on product price and cost variance in C2C E-market transaction can be excluded. In China's domestic C2C E-commerce, there's always "fixed price" pattern. The sellers are usually at a disadvantage position when bargaining with suppliers. Therefore, different from the auction transaction research by House and Wooders (2006) and Chrysanthos (2005), the impact of reputation on current commodity's price and cost can be excluded [7] [8].

2) The influence of reputation on sellers' profit is mainly reflected in the sales volume. Different from traditional competitive market, C2C E-commerce has the following features: Multi-platforms with bilateral users, multi-business access, homogeneity of goods, being substituted easily. Hence, the switching cost of buyers can be excluded. The influence of reputation on sellers' profit is mainly 
reflected in the sales volume.

3) There's a long period of game time for C2C E-commerce transaction. In the platform like Taobao, the sellers are usually stable to provide long-term supply, so buyers and sellers have enough game time, which is different from eBay trading pattern.

\subsection{Model Assumption}

In the setting of $\mathrm{C} 2 \mathrm{C} \mathrm{E}$-commerce, we consider one single product transaction between one seller $X$ and several buyers $Y$ and set a game model of unilateral moral hazard. First, the sellers $X$ are grouped into two types: irrational sellers $\left(A_{1}\right)$ and rational sellers $\left(A_{2}\right)$. Buyers $Y$ are only irrational $\left(A_{1}\right)$. Irrational people will prefer honest trading strategy $\left(a=a_{1}\right)$, while rational people will choose between honest trade strategy $\left(a=a_{1}\right)$ and fraud trade strategy $\left(a=a_{2}\right)$ based on expected utility function.

Because of asymmetric information and the non-contractual feature of product service quality, sellers have information superiority when they take action afterwards, which is unilateral moral hazard. On the other hand, since in $\mathrm{C} 2 \mathrm{C}$ e-market the products has the feature of homogeneity and the platform can't be completely replaced, buyers will prefer to trade with irrational sellers $\left(A_{1}\right)$ based on reputation rating. In conclusion, this thesis defines reputation as follows: reputation is the possibility of sellers $X$ to become irrational $\left(A_{1}\right)$ type of sellers.

The letters are denoted as follows:

1) $T$ and $n$ represent the total times of game and game period respectively, $1 \leq n \leq T$;

2) $p$ means the product price per unit;

3) $c$ indicates the product cost per unit;

4) $q(n)$ means aggregate demand of the product and the demand volume will change dynamically with different times of games;

5) $\pi$ means the total revenue of sellers;

6) $\sigma$ represents discount factor $0 \leq \sigma \leq 1$;

7) $f(n)$ represents sellers' reputation in $n$ period $0 \leq f(n) \leq 1$;

8) $r$ and $k$ represents the possibility of irrational sellers to take honest actions and the possibility of rational sellers to take honest actions respectively,

$0 \leq r \leq 1, \quad 0 \leq k \leq 1$.

The assumptions are as follows:

1) Buyers and sellers have enough game time, $T \geq 1$

2) Various sellers' familiarity with their own market environment and related experience differ, that is to say $A_{1}$ type of sellers are better at honest trade than $A_{2}$ type of sellers. That results in $r>k$.

3) Buyers' impression on sellers' reputation has a priori probability distribution, $f(1)=f$;

4) In game period, $p$ and $c$ are constants and $q(n)$ will change dynamically with reputation. 
5) If the seller is assumed to take fraud action, the cost to disguise itself as an honest seller is too much and the cycle is too long. Therefore once the seller takes fraud action, it will no longer take honest conduct again.

\section{The Evolution of Reputation in Multi-Cooperation Phases}

In one period of the game, fraud and not buying are often balanced. It's an inefficient balanced result, which will reduce the market share deduction and ruin the integrity system. When we take account of multi-phases of the game, the implicit incentive mechanism like reputation will take effect on the equilibrium result.

\subsection{Formation of Reputation}

Figure 1 shows the formation of sellers' reputation in C2C E-commerce transaction. Firstly, we make a random selection for the type of $X\left(A_{1}, A_{2}\right)$. In $n$th period of the game, buyers $Y$ will decide its purchasing volume $q(n)$ based on sellers $X(n-1)$ th period's reputation $f(n-1)$. Then sellers $X$ will make a delivery $\left(a_{1}, a_{2}\right)$ in $n$th period. After the delivery, buyers $Y$ will adjust $f(n-1)$ to form sellers' reputation $f(n)$ in $n$th period based on sellers $Y$ s performance. In the following game periods, the above steps will be repeated until the end of the game.

Sellers' performance in $(n-1)$ th period will influence their reputation $(f(n))$ in $n$th period

$$
\left\{\begin{aligned}
f(n) & =p\left(A_{1} \mid a_{2}\right)=\frac{p\left(A_{1}\right) \times p\left(a_{2} \mid A_{1}\right)}{p\left(A_{1}\right) \times p\left(a_{2} \mid A_{1}\right)+p\left(A_{2}\right) \times p\left(a_{2} \mid A_{2}\right)} \\
& =\frac{(1-r) \times f(n-1)}{f(n-1) \times(1-r)+(1-f(n-1)) \times(1-k)} \quad\left(a(n-1)=a_{2}\right) \\
f(n) & =p\left(A_{1} \mid a_{1}\right)=\frac{p\left(A_{1}\right) \times p\left(a_{1} \mid A_{1}\right)}{p\left(A_{1}\right) \times p\left(a_{1} \mid A_{1}\right)+p\left(A_{2}\right) \times p\left(a_{1} \mid A_{2}\right)} \\
& =\frac{r \times f(n-1)}{f(n-1) \times r+(1-f(n-1)) \times k} \quad\left(a(n-1)=a_{1}\right)
\end{aligned}\right.
$$

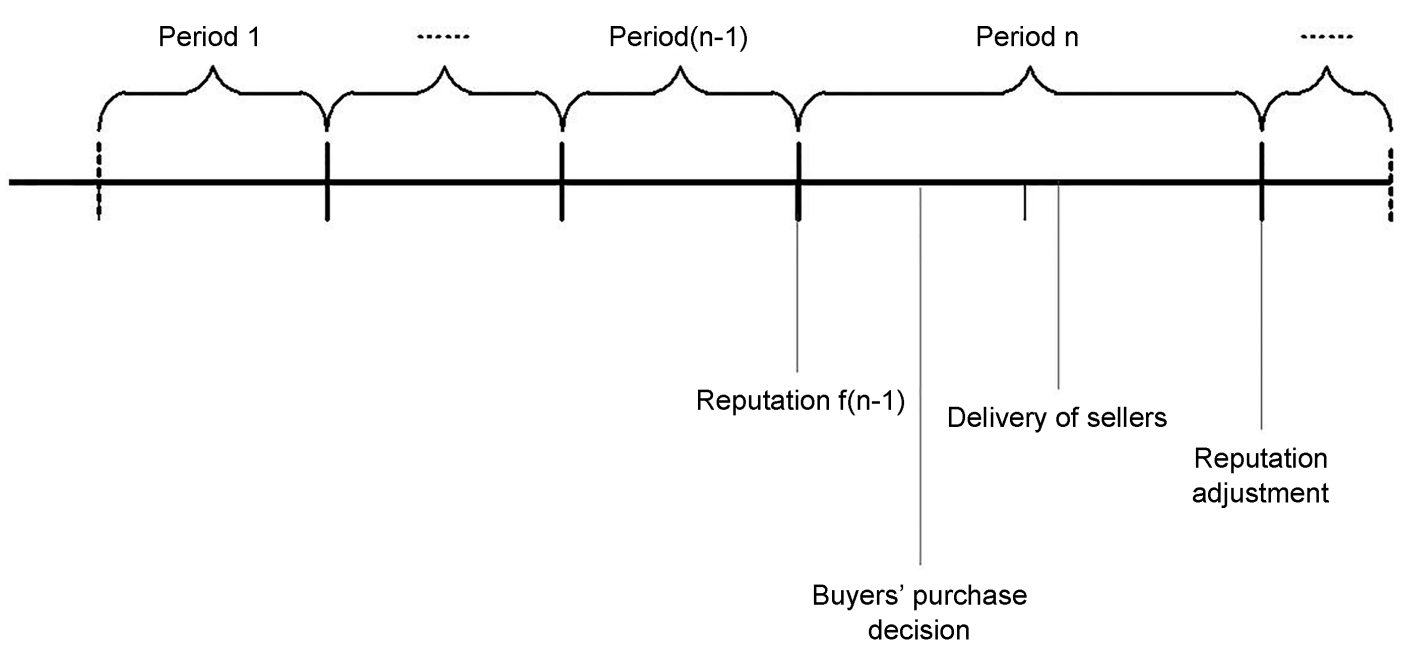

Figure 1. Model of dynamic formation for C2C sellers' reputation. 
To further verify the rules of reputation dynamic change in the process of game:

$$
\left\{\begin{aligned}
\frac{f(n)}{f(n-1)} & =\frac{(1-r)}{f(n-1) \times(1-r)+(1-f(n-1)) \times(1-k)} \\
& <\frac{(1-r)}{f(n-1) \times(1-r)+(1-f(n-1)) \times(1-r)}=1 \quad\left(a(n-1)=a_{2}\right) \\
\frac{f(n)}{f(n-1)} & =\frac{r}{f(n-1) \times r+(1-f(n-1)) \times k} \\
& >\frac{r}{f(n-1) \times r+(1-f(n-1)) \times r}=1 \quad\left(a(n-1)=a_{1}\right)
\end{aligned}\right.
$$

The above formula shows that if sellers $X$ take honest action in $(n-1)$ th period, their reputation will be improved; if sellers take fraud action in $(n-1)$ th period, their reputation will be lowered.

By the same analogy, in $T$ th $(T=2,3 \cdots)$ period of game, the rules for reputation change are as follows: 1 ) when $X$ begins to take moral hazard behavior in $n$th period, its reputation will decrease to zero,

$f(n-1)>f(n)>f(n+1) \cdots>f(T) \approx 0 ; 2)$ when $X$ always takes honest action, its reputation will continuously improve and is close to perfection,

$f(1)<f(2)<\cdots<f(T) \approx 1$.

\subsection{Change of Reputation}

In order to verify the conclusions about the evolution of reputation and conduct correlation analysis, this thesis makes the following settings:

$r=0.8, k=0.5(f=0.1, f=0.3, f=0.5, f=0.7)$,

$r=0.8, f=0.5(k=0.1, k=0.3, k=0.5, k=0.7)$,

$k=0.5, f=0.5(r=0.5, r=0.7, r=0.9, r=1)$. Figures $2-4$ show the process of reputation change when there's no moral hazard behavior.

Figure 2 shows the process of reputation change when $r=0.8, k=0.5$. The solid lines show the process of reputation when there's no moral hazard behavior and the dashed lines when there's moral hazard behavior. Figure 3 shows the process of reputation change when $r=0.8, f=0.5$. The solid lines show the process of reputation when there's no moral hazard behavior and the dashed lines when there's moral hazard behavior

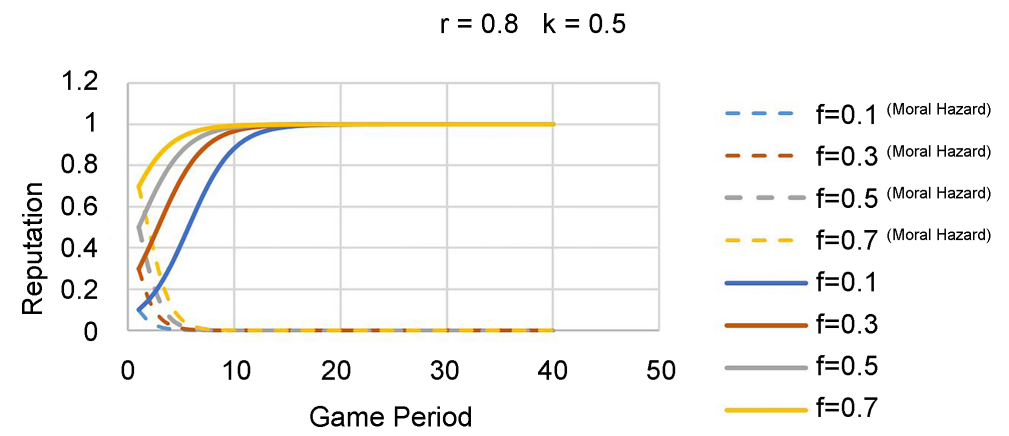

Figure 2. The impact of $f$ on reputation change. 
Figure 4 shows the process of reputation change when $k=0.5, f=0.5$. The solid lines show the process of reputation when there's no moral hazard behavior and the dashed lines when there's moral hazard behavior.

We can make following conclusions from the above figures:

1) Change of reputation can effectively reflect sellers' moral hazard behavior. Sellers without moral hazard behavior can keep improving their reputation value; while when sellers begin to take moral hazard behavior in the game period, their reputation value tends to decrease apparently.

2) Reputation mechanism can have an effective incentive effect. From Figures $2-4$, we can see that when repeated game reaches certain times, different values of $r, f$ and $k$ will be almost no impact on reputation of sellers, who take different actions. This means that reputation mechanism has strong incentive effect and can achieve significant results in limited time of the game.

3) The initial reputation change rate is related to $r, f$ and $k$. As for the sellers who always take honest action, with the increase of $r$ and $k$ value, or with the decrease of $k$ value, the curvature change rate of sellers' reputation is high at the beginning. But for sellers who take moral hazard action, with the increase of $r$ and $k$ value, or with the decrease of $k$ value, the curvature change rate of sellers' reputation is high at the beginning.

\subsection{Repeated Game Based on Unilateral Moral Hazard}

From the above assumption, in each period of game the impact of sellers' reputation on product price and cost can be excluded. So sellers' reputation mainly

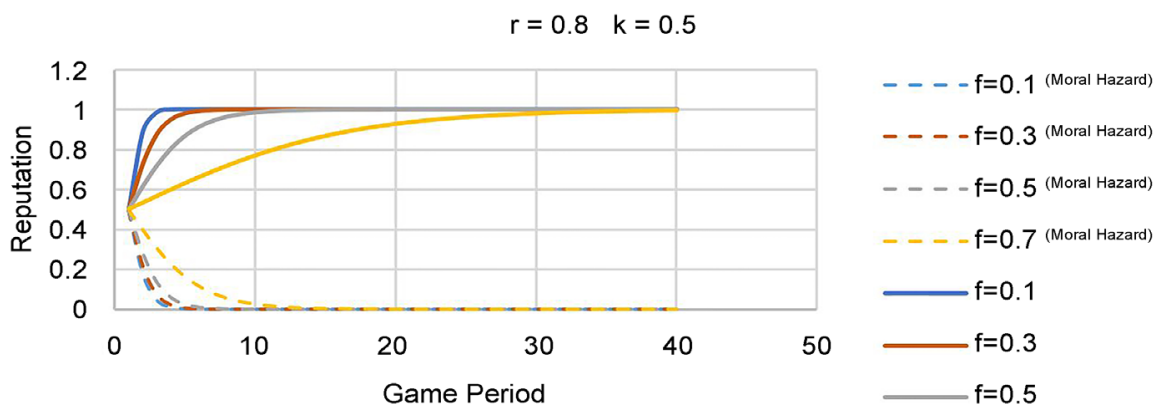

Figure 3. The impact of $k$ on reputation change.

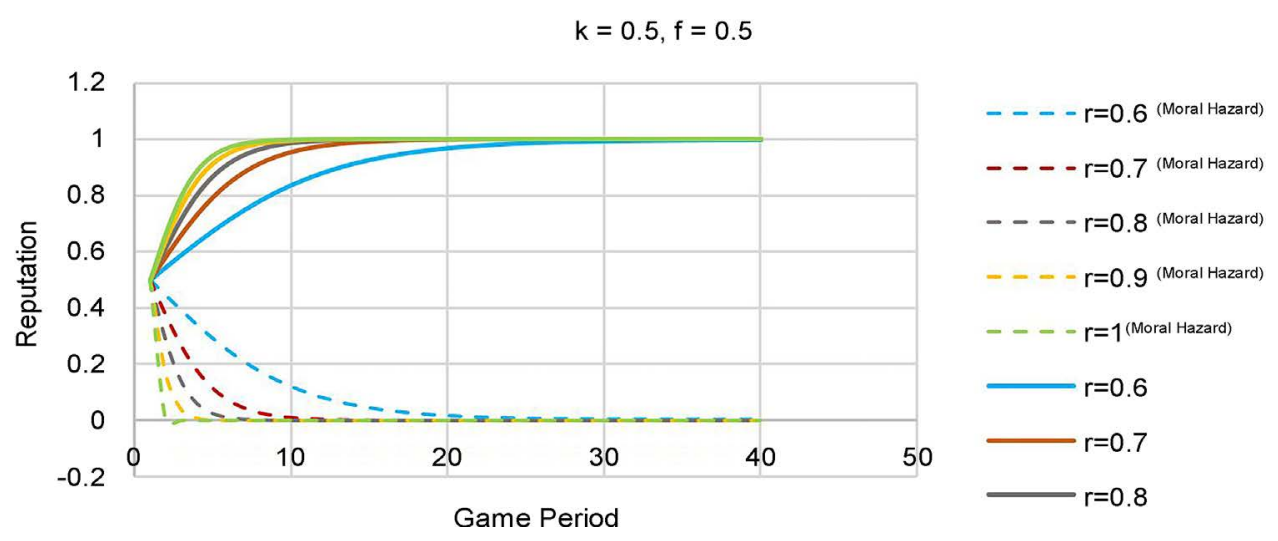

Figure 4. The impact of $r$ on reputation change. 
impact product sales volume. In this thesis, $q(n)=f(n) \times q(n-1)$ and $f(1)=q$, which is the maximum demand.

When sellers $X$ take fraud action $\left(a_{2}\right)$ in the first period, sellers expected profit is $\pi_{1}=\sum_{K=1}^{T} \sigma^{k} \times f(K) \times p \times q$; When they take honest action inn 7 th transaction, their expected profit is $\pi_{2} \mathrm{~s}$ :

$$
\begin{gathered}
\pi_{2}=\sum_{k=1}^{T} \sigma^{k} f(k) \times(p-c) \times q=\sum_{k=1}^{T} \sigma^{k} \times(p-c) \times q . \\
\pi_{1}-\pi_{2}=
\end{gathered}
$$

1) When discount factor $\sigma=1$ :

When and only when $T-n>\frac{c}{p-c}$, sellers will keep conducting honest transactions in Tth period.

2) When discount factor $0<\sigma<1$ :

$$
\begin{gathered}
\pi=\sum_{K=1}^{n-2} \sigma^{k} \times(p-c) \times q+\sigma^{n-1} \times p q \\
\pi_{1}=q \times(p-c) \times \frac{1-\sigma^{T+1}}{1-\sigma}
\end{gathered}
$$

Let's compare $\pi$ and $\pi_{1}$. When and only when $\frac{1-\sigma^{T+1}}{1-\sigma}>\frac{p}{p-c}=1+\frac{c}{p-c}$, sellers will always conduct honest transactions.

3) When the number of game times tends to infinity:

When the number of game times $T$ tends to infinity, then $\sigma^{T+}$ tends to 0 . At this point, when and only when $\frac{1}{1-\sigma}>\frac{c}{p-c}$ and $1>\sigma>\frac{2 c-p}{c}, \frac{p}{c}>1$, sellers will choose to always conduct honest transactions.

\subsection{Analysis and Conclusions}

In real world of trade, Most of the mutual transactions times in market is more than twice. In repeated game, the participants are likely to sacrifice long-term interests to gain immediate interests. When there's asymmetric information, consumers don't know the type of the sellers. Hence, sellers are more likely to establish a good reputation to get generous profits in future. Before consciously purchasing, buyers should consider sellers' reputation to obtain greater benefits or minimize transaction risk. In e-commerce market where there's serious information asymmetry, reputation, as part of sellers' value, has become a key performance indicator to decide whether buyers trade with sellers (Ma Huiming et al., 2005).

In the setting that price and cost remain unchanged, we just consider discount factor $\sigma$. It reflects both time value of the assets in e-market and sellers' confidence in future development of e-market. Therefore, when there's unlimited times of game, price becomes less compared with cost, discount factor becomes bigger, sellers' expected gain becomes smaller. Therefore, the non-financial incentive effect of reputation will be weakened. Based on above analysis, we should keep market in order, boost sellers' confidence to reduce $\sigma$, and ultimately reduce the dishonest behavior. 
From another perspective, if discount factor $\sigma$ is a certain value, it requires $2-\sigma<\frac{p}{c}(0<\sigma<1)$ and the ratio of price and cost keeps above 1 . Since there's "fixed price" trade model and sellers usually don't have the ability to influence market price, we should consider reducing ratio of price and cost by cutting cost to have a restriction effect. Specifically, we can reduce the transaction cost by optimizing various supply chain processes in C2C E-market and by reasonable payment, distribution and communication channels.

Lastly, supervisors in market should improve the transparency of e-commerce transactions and reinforce stakeholders' restriction for the reputation and dishonest behavior of sellers and buyers. They should also strengthen the supervision of e-market transaction and improve the legislation for e-commerce.

\section{Conclusions and Enlightenment}

C2C e-commerce is an emerging transactional model in the age of network economy. Over years of development by leaps and bounds, it has become an important market force. This thesis analyzes the decisions made by sellers in $\mathrm{C} 2 \mathrm{C}$ e-commerce based on one-game model and repeated-game model. We can make the following conclusions:

1) Without taking into account reputation and other non-financial incentive factors, sellers in $\mathrm{C} 2 \mathrm{C}$ trade market will use their information advantage to take risky actions morally in exchange for large gains in a single game period. But this will result in fraud action or no deal and inefficient equilibrium, which is not conducive to long-term stable development of the market.

2) The nature of reputation is sellers and buyers' perception of what type each other is, based on information exchange in a long period of game. Sellers' reputation is influenced by their previous behaviors. With more and more times of game, the impact of priori probability on sellers' reputation is gradually reduced, sellers' initial reputation degree becomes lower and the honest behavior will improve its reputation. Therefore, sellers can take positive actions to improve in a certain period of time.

3) In repeated game, reputation can have restriction effect on C2C sellers' moral hazard actions. The factor which influences sellers' action is the discount value of short-term gains and long-term gains. As long as discount value of future gains is more than the gains earned by taking moral hazard behavior, reputation can effectively suppress moral hazard behavior.

By introducing reputation effect, we should reinforce sellers' honest action from the following aspects: 1) To keep market in order and enhance sellers' confidence; 2) To integrate supply chain resources and reduce transaction cost; 3) To enhance the transparency of e-commerce transactions, strengthen the supervision of e-commerce transactions and improve the legislation for e-commerce.

\section{References}

[1] Li, L., Yang, W.S., Wen, S. and Cai, S.Q. (2005) Transaction Risk Control by Cy- 
bermediary. Journal of Management Sciences in China, 3, 56-62.

[2] Xie, T.S., Zhao, Y.S and Li, J. (2009) Keep Away from the Moral Hazard of Third Party Logistics Provider. Journal of Systems \& Management, 2, 137-141.

[3] Zhou, L.A., Zhang, W.Y., Gu, Q.L. and Shen, Y. (2006) The Value of Reputation: Evidence from Online Auctions. Economic Research Journal, 12, 81-91.

[4] Jin, X.J. and Yu, J.J. (2006) Information Asymmetry, Reputation Effect and Cooperation Equilibrium. Social Science, 9, 72-75.

[5] Zhang, J.J., Zhao, J., Zhang, H.J. and Zhang, Y.X. (2013) Study on Peputation Evolution in Perishable Product Supply Chain with Moral Hazard. Chinese Journal of Management Science, 1, 181-184.

[6] Troy, J.S. and Sridhar, N. (2002) Trust Worthiness in C2C Online Markets. Communications of the ACM, 45, 45-49. https://doi.org/10.1145/585597.585600

[7] Bakos, Y. and Dellarocas, C. (2003) Cooperation without Enforcement: A Comparative Analysis of Litigation and Online Reputation as Quality Assurance Mechanisms. MIT Sloan School of Management Working Paper, 3, 42-53.

[8] Daniel, H. and Wooders, D. (2006) Reputation in Auctions: Theory, and Evidence from eBay. Journal of Economics \& Management Strategy, 15, 255-548.

[9] Ji, Y.D., Li, P. and Zhang, G.Z. (2010) The Value of Seller's Reputation in Online Auction: Evidence from the Stamp. Chinese Journal of Management, 8, 1165-1169.

[10] Li, W.A., Wu, D.S and Xu, H. (2007) Reputation in China's Online Auction Market: Evidencefrom the Taobao Website. Nankai Business Review, 10, 36-46.

[11] Pan, Y. and Qiao, X.D. (2012) Adverse Selection and Local Research on the Reputation Mechanismin E-Commerce Market in China: A Case Study of Taobao.Com. Journal of Business Economics, 1, 13-18.

\section{Submit or recommend next manuscript to SCIRP and we will provide best} service for you:

Accepting pre-submission inquiries through Email, Facebook, LinkedIn, Twitter, etc. A wide selection of journals (inclusive of 9 subjects, more than 200 journals)

Providing 24-hour high-quality service

User-friendly online submission system

Fair and swift peer-review system

Efficient typesetting and proofreading procedure

Display of the result of downloads and visits, as well as the number of cited articles

Maximum dissemination of your research work

Submit your manuscript at: http://papersubmission.scirp.org/

Or contact jss@scirp.org 